\title{
Effects of pesticides and related organic compounds in the sea
}

\author{
W. Ernst \\ Institut für Meeresforschung Bremerhaven; \\ Am Handelshafen 12, D-2850 Bremerhaven, Federal Republic of Germany
}

\begin{abstract}
The majority of organic chemicals identified so far in the sea are pesticides and products of technical use; most contain chlorine. Only a limited amount of the actual pollutant load is detectable because few data for "unconventional" pollutants are available. In view of the considerable structural variety of the large number of chemicals produced, there is a need for prediction measurements of bioconcentration and toxic effects. Physico-chemical data may be used for predicting bioconcentration and life-cycle toxicity tests for the estimation of safe levels. The degree of biomagnification via food chains increases with half lives of the pollutants. When comparing pollutant concentrations with toxicological data it becomes apparent that estuaries and coastal areas deserve special concern, whereas pollutant levels of open ocean waters are unlikely to endanger marine life at present.
\end{abstract}

\section{INTRODUCTION}

Organic chemicals of anthropogenic origin are an increasing threat to the marine environment. More than 60000 common chemicals are in use and some hundred new chemicals per year will be added. Obviously, many of them will reach estuaries, coastlines and even the open sea via well-known routes such as rivers, atmospheric transport or dumping. Some of these chemicals exhibit considerable persistence in the environment and are produced in large quantities on a scale of up to a million tons per year, so that they have now become detectable compounds in sea water, sediments and biota. It is, on the other hand, the sensitivity and specificity of analytical methods that governs the degree of recognition of the present pollutant load in the sea. Many compounds in the sea are still unknown, but they may occur at comparatively high concentrations; others, that will show up by improved analytical techniques, may be of negligible significance.

It would go beyond the scope of this paper to give a complete review of the vast field of interrelations between organic pollutants and living and dead matter in the sea. I consider here the following questions: (a) Which organic substances do actually and preferably occur in the sea and what are their concentrations? (b) What is their principal fate? (c) What are the effects that can be observed or expected? (d) How can the results be used in a risk assessment for these chemicals?

The question of risk assessment has been emphasized; probably the high production of organic chemicals will continue and new compounds will substitute those whose 
environmental behaviour is already well known. It is therefore necessary to develop reliable laboratory methods for predicting relationships between the environmental effects and substance parameters. This will perhaps enable us to make more appropriate appraisals before a new substance is released.

\section{SUBSTANCES AND THEIR CONCENTRATIONS}

Organic substances identified so far in the sea comprise: (1) pesticides and their metabolites; (2) products of technical use and their by-products. Figure 1 shows the concentrations of various compounds in the surface water of near-shore waters and the open sea. Pollutant concentrations from both areas are compared to demonstrate the higher pollution of estuaries and coastal waters and the dilution effects. Levels in the

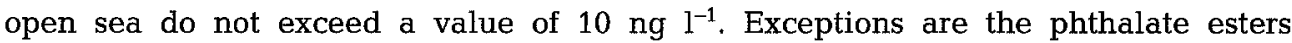
dibutylphthalate (DBP) and di-2-ethylhexylphthalate (DEHP), which show comparatively high concentrations in the Gulf of Mexico but DBP could not be detected in the northern Atlantic (Giam et al., 1978). Other chemicals in Figure 1, such as pentachlorophenol (PCP), can be detected in the German Bight at low concentrations but may be undetectable in ocean waters (Weber \& Ernst, 1978); $\gamma$-hexachlorocyclohexane $(\gamma$ $\mathrm{HCH}$ ) and its isomer $\alpha-\mathrm{HCH}$ may behave correspondingly.

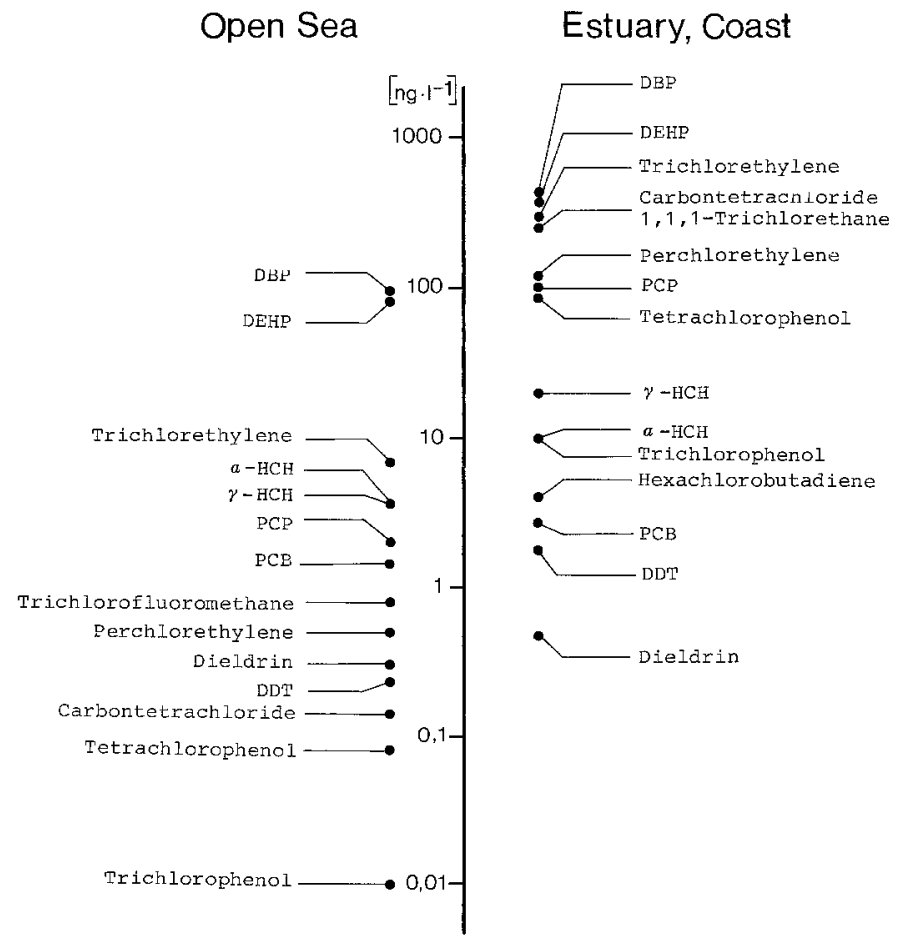

Fig. 1. Concentration of various organic substances in sea water of the open sea, estuaries and coastal areas (after Murray \& Riley, 1973; Pearson \& McConnell, 1975; Stadler, 1977; Ernst \& Weber, 1978; Giam et al., 1978; Weber \& Emst, 1978) 
It should be noted that values in Figure 1 were obtained in surface waters but concentrations decline with increasing depth. Values presented for estuaries and coastal waters are considerably higher; they vary with tidal fluxes and emission rates. Polychlorinated biphenyls are usually determined gas chromatographically via pattern recognition using PCB-types such as Aroclor 1254 or Clophen A 60. More precise evaluation can be expected with glass-capillary gas chromatography, which more effectively separates individual compounds. More than 80 different chlorobiphenyls ranging from trichloro- to octachlorobiphenyls (Zell et al., 1978) were detected in livers of fish from the North Sea using this method. Hexachlorobenzene, not listed in Figure 1, is a further pollutant in the marine environment and although its detection in marine animals demonstrates its presence in sea water, no quantitative data are reported for sea water. It seems that at present only a minor part of the actual load of organic pollutants is well known. Group parameters such as organically bound chlorine illustrate that for example, sea water from the Oslo Fjord contained $40-195 \mathrm{ng} \mathrm{l}^{-1}$ of organic chlorine but only 1-2 ng $\mathrm{l}^{-1}$ could be assigned to PCB as the most prominent compound; similar findings were made with organically bound chlorine in fish oils (Lunde \& Steinness, 1975; Lunde et al., 1975). A load of more than $10^{4}$ tons/year organically bound chlorine as lipophilic organic chlorine compounds and 300 tons/year cholinesterase inhibitors as parathion equivalents are discharged by the River Rhine; $90 \%$ of these compounds will escape gas chromatographic detection (Poels et al., 1978). Current analytical work in our laboratory indicates that a number of compounds previously unknown as marine pollutants can be detected in North Sea water after appropriate solvent extraction and using analytical techniques such as computerized gas chromatography combined with mass spectrometry. The compounds include chlorinated aromatics, organophosphorous compounds and PAH's (Weber, in preparation).

\section{BIOCONCENTRATION AND BIOMAGNIFICATION}

Historically, studies on the organohalogen compounds and especially DDT led to intensive research on bioconcentration phenomena in aquatic environments. Many data have been obtained but few are directly comparable because of methodical variations, e.g. differences in species, maintenance of organisms, substance concentrations, temperature, salinity, substrate carriers, kinetic variations. Nevertheless, some details derived from these investigations 'may contribute to the quantitative description of the processes of uptake and release of chemicals in organisms. Bioconcentration occurs directly by uptake from water or indirectly via food chains. Most work has been done on the former. Bioconcentration potentiais for organic pollutants may be described by the concentration factor $(\mathrm{CF})$, the ratio of the concentration in animals to that in water. It is now increasingly acknowledged that bioconcentration factors should be determined at steady-state conditions in order to obtain calculable data.

In view of the many organic substances that are potential environmental pollutants, it is not surprising that a major objective in this field has been the collection of basic data for predictions. Among the physico-chemical parameters recently introduced for this purpose, the most promising are water solubility and partition coefficients. A correlation of bioconcentration factors with water solubility is presented in Figure 2. All values measured are obtained at steady state from experiments with bivalves and fish. The 


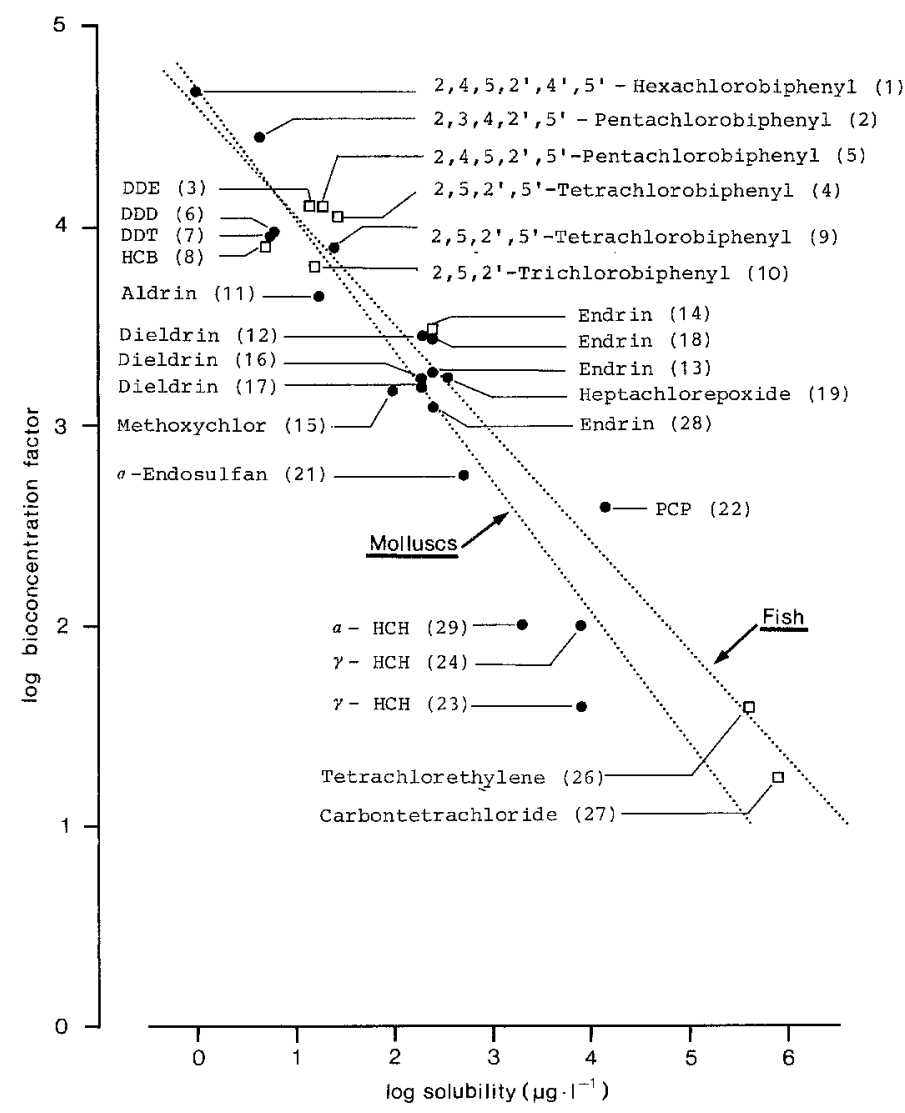

Fig. 2. Correlation between water solubility and bioconcentration factors of organic substances in fish and bivalves. Number refer to substances: No. 1, 2, 9 (Vreeland, 1974); No. 3, 4, 5, 10 (Metcalf et al., 1975); No. 6, 13, 17, 19, 21, 24, 29 (Ermst, 1977); No. 7, 11, 15, 16, 23, 28 (Butler, 1971); No. 8, 14,

26, 27 (Neely et al., 1974); No. 12, 18 (Mason \& Rowe, 1976); No. 22 (Ernst, 1979)

correlation reveals that the bioconcentration potential increases with decreasing solubility. At present such a relationship must be regarded as hypothetical because determinations of solubilities as low as indicated are difficult and contradictory results are reported in the literature (Gunther et al., 1968; Weil et al., 1974; Haque \& Schmedding, 1975; Chiou et al., 1977).

The use of partition coefficients for these correlations appears to be more conspicuous because the distribution of a chemical in an organism can be regarded as a partition process operating between the aqueous phase and the organic compartment. Partition coefficients for this purpose refer to the $n$-octanol-water system. Experimentally, they can more easily be obtained than solubility data and are furthermore calculable from chemical structures via fragment constants (Leo, 1975). A correlation of these data with bioconcentration factors has been shown for fish according to the equation log (bioconc. factor $)=0.542 \log$ (partition coeff.) +0.124 (Neely et al., 1974). A similar correlation for bivalves is exhibited in Figure 3 using partition coefficients from various authors (Neely et al., 1974; Leo, 1975; Chiou et al., 1977). It should be noted again that the logarithms of 


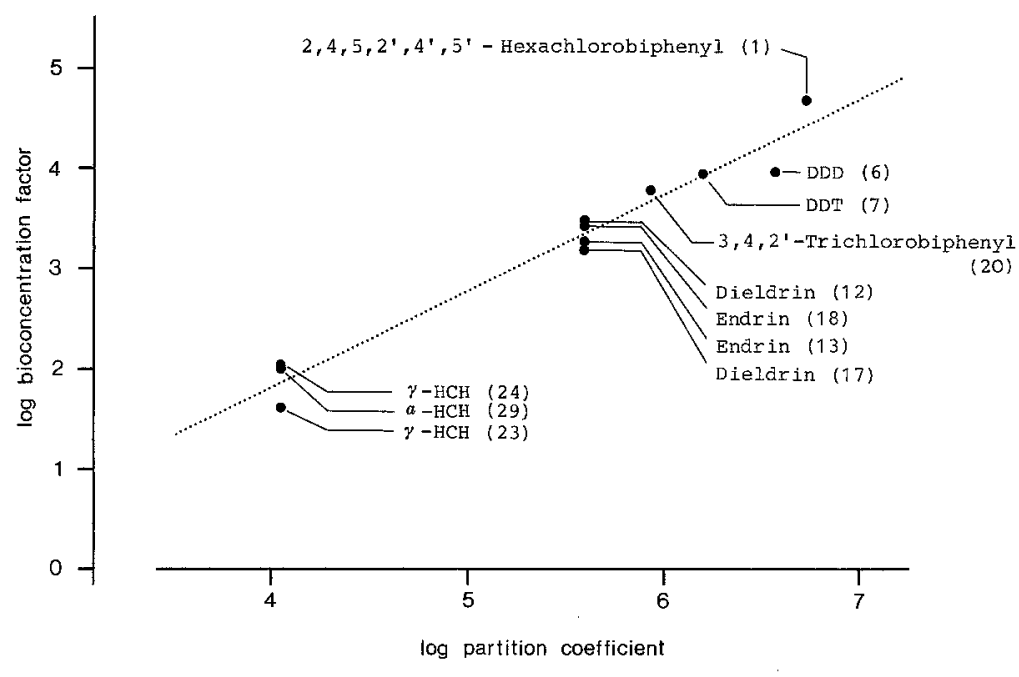

Fig. 3. Correlation between partition coefficients and bioconcentration factors of organic substances in bivalves. Number refer to substances: No. 1, 20 (Vreeland, 1974); No. 6, 13, 17, 24, 29 (Ernst, 1977); No. 7, 23 (Butler, 1971); No. 12, 18 (Mason \& Rowe, 1976)

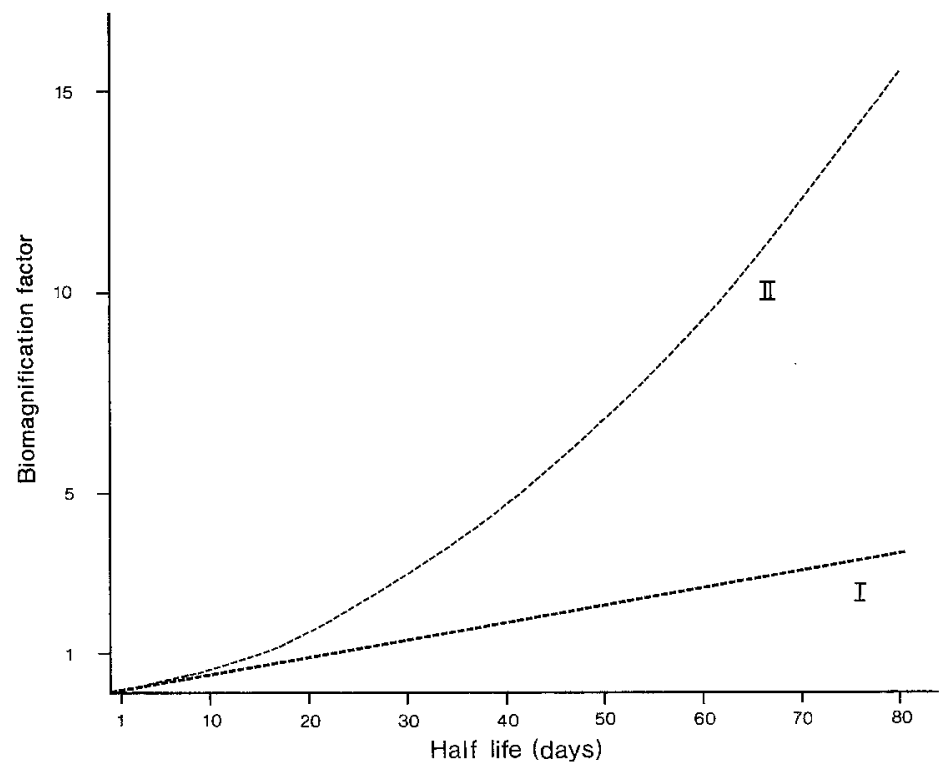

Fig. 4. Correlation between elimination half lives and biomagnification in two consumer levels. I, II: calculated curves for a feeding rate of $3 \%$ of body weight. Biomagnification factor $1=100 \%$ additional uptake of substance via food in relation to uptake from water 
variables are plotted and therefore these figures should be used with some care, but it seems feasible to derive preliminary information on bioconcentration prediction from work of this type.

Food-chain transfer of organic pollutants should not be neglected in the overall accumulation processes. Although sufficient results are available on the significance of substance accumulation via food, no clear-cut conception can so far be obtained among the controversial suggestions and results.

In order to estimate the share of biomagnification, a model has been developed using half lives or elimination constants (Ernst, in preparation). In Figure 4 biomagnification factors from this model are plotted versus half lives for two subsequent consumer levels. Although the model may be adapted to varying parameters, the following assumptions have been made: (a) the concentration of the substance in water is constant; (b) Consumer II feeds exclusively on Consumer I at a constant daily rate; (c) the pollutant present in Consumer I is quantitatively absorbed by Consumer II; (d) the bioconcentration factors from water and the elimination rate constants are the same for the consumers and the processes are in equilibrium; (e) degradation of the substance does not occur and relevant physiological differences between the consumers do not exist. Although the biomagnification factors in Figure 4 are over-simplified, some limiting estimates can be made. Figure 4 shows that substances exhibiting half lives of about 10-20 days will at most lead to levels twice as high as those obtained via bioconcentration from water. A substantial increase of one order of magnitude will occur only at high half lives but hardly at Consumer level I. It should be noted that, in contrast to the process of uptake from water, more time is needed before the biomagnification becomes apparent and 4 to 5 half lives are required to attain more than $90 \%$ of the theoretical value.

\section{METABOLISM}

The structure of organic molecules may be fundamentally modified in living organisms. Generally this results in the production of less harmful substances, but it is possible for metabolites to exhibit properties more detrimental than those of the parent compounds, e. g. higher degrees of persistence or elevated toxicity. In view of these important facts, surprisingly little work has been done on metabolic studies in aquatic species compared with terrestrial species. This may be due to difficulties such as high toxicity and low transformation rates for most organic compounds. Brodie \& Maikel (1962) suggested that fish, for example, is lacking in the ability to metabolize foreign compounds, but more recent findings demonstrate that marine species do indeed have a mixed function oxidase system located in the microsomes which is responsible for the oxidation of organic compounds (Pohl et al., 1974).

Some pathways of metabolic transformations are shown in Figure 5 for different species. Pentachlorophenol can easily be conjugated with sulphuric acid in bivalves (Kobayashi et al., 1970; Ernst, 1979) or with glucuronic acid in fish (Glickman et al., 1977). The chlorobiphenyls are usually stable, especially the higher chlorinated ones, but a substantial hydroxylation was observed in the marine polychaete Nereis virens (Ernst et al., 1977) and a methylsulphone metabolite was discovered in seals (Jensen \& Jansson, 1976). DDE and DDD are well known metabolites of DDT; Figure 5 shows a hydroxylation product of DDE isolated from faeces of seals (Sundström et al., 1975) and a 
methylsulphone metabolite of DDE derived from seal blubber (Jensen \& Jansson, 1976). Phthalate esters, such as di-2-ethylhexyl-phthalate, may be transformed to mono-esters and phthalic acid (Stalling et al., 1973).

The metabolites shown in Figure 5 are more polar than the parent compounds. When we go back very briefly to the difficulties in the analysis of pollutants, we can easily conclude that these compounds will remain undetected in the usual analytical systems arranged for non-polar compounds. The initial metabolic modification of the molecule will probably facilitate the subsequent total break down. On the other hand, it should not be overlooked that a reaction like the conjugation of phenols does not alter the structure of the compound; in this case, the free phenol will be available when the conjugate is hydrolyzed.

A
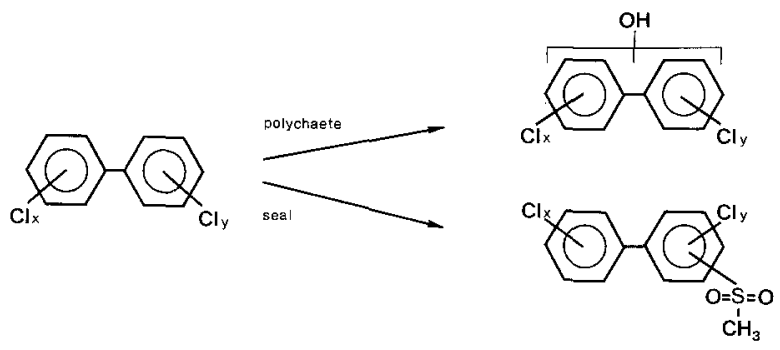

$\mathrm{B}$<smiles>Clc1c(Cl)c(Cl)c(Cl)c(Cl)c1Cl</smiles><smiles>C1C[C@H]2CC[C@H](C1)C2</smiles><smiles>O=S(=O)(O)c1c(Cl)c(Cl)cc(Cl)c1Cl</smiles><smiles>C[13CH3]</smiles>

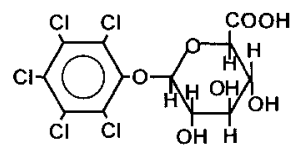

C<smiles>Clc1ccc(C(Cl)(Cl)c2ccc(Cl)cc2)cc1</smiles><smiles>CI=[IH]</smiles><smiles>Oc1cccc(C(Cl)(Cl)c2ccc(Cl)cc2)c1</smiles><smiles>C[Sb](=O)(O)(O)c1cc(-c2ccc(Cl)cc2)ccc1Cl</smiles>

D

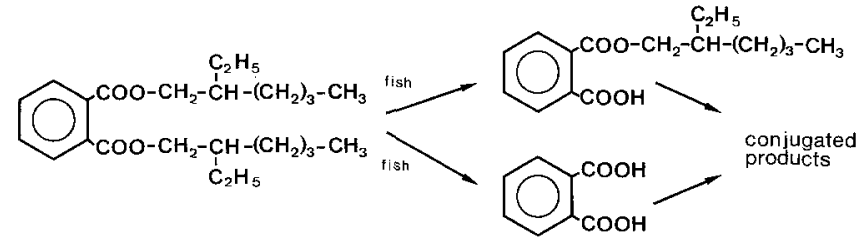

Fig. 5. Metabolic degradation of organic substances in aquatic animals. A: Polychlorinated biphenyls, B: pentachlorophenol, C: DDT, D: di-2-ethylhexylphthalate 


\section{TOXICITY}

The occurrence of organic chemicals in the marine environment requires evaluation of the effects that they may have directly on a species or indirectly on the marine ecosystem. In aquatic toxicology, the acute toxicity test for invertebrates and fish enables estimation of the exposure concentration resulting in $50 \%$ mortality of the test animals within 48 or $96 h_{i}$ it is expressed as $\mathrm{LC}_{50}$. The numerical value of the $\mathrm{LC}_{50}$ has assumed special importance as an index of toxicity, but with the incorporation of highly persistent substances with high bioconcentration potentials and low water solubilities it can provide only marginal information. Toxicologically it is inadequate and many biological effects of pollutants may not be evident. When testing accumulating substances, the $\mathrm{LC}_{50}$ may decrease considerably with increasing exposure periods (Eisler, 1970; Holden, 1973); neither this, nor the possibility that the test compounds may evaporate or be adsorbed to the walls of the tanks in static tests, was sufficiently considered in early experiments. But there are many other factors affecting the $\mathrm{LC}_{50}$ values of organic

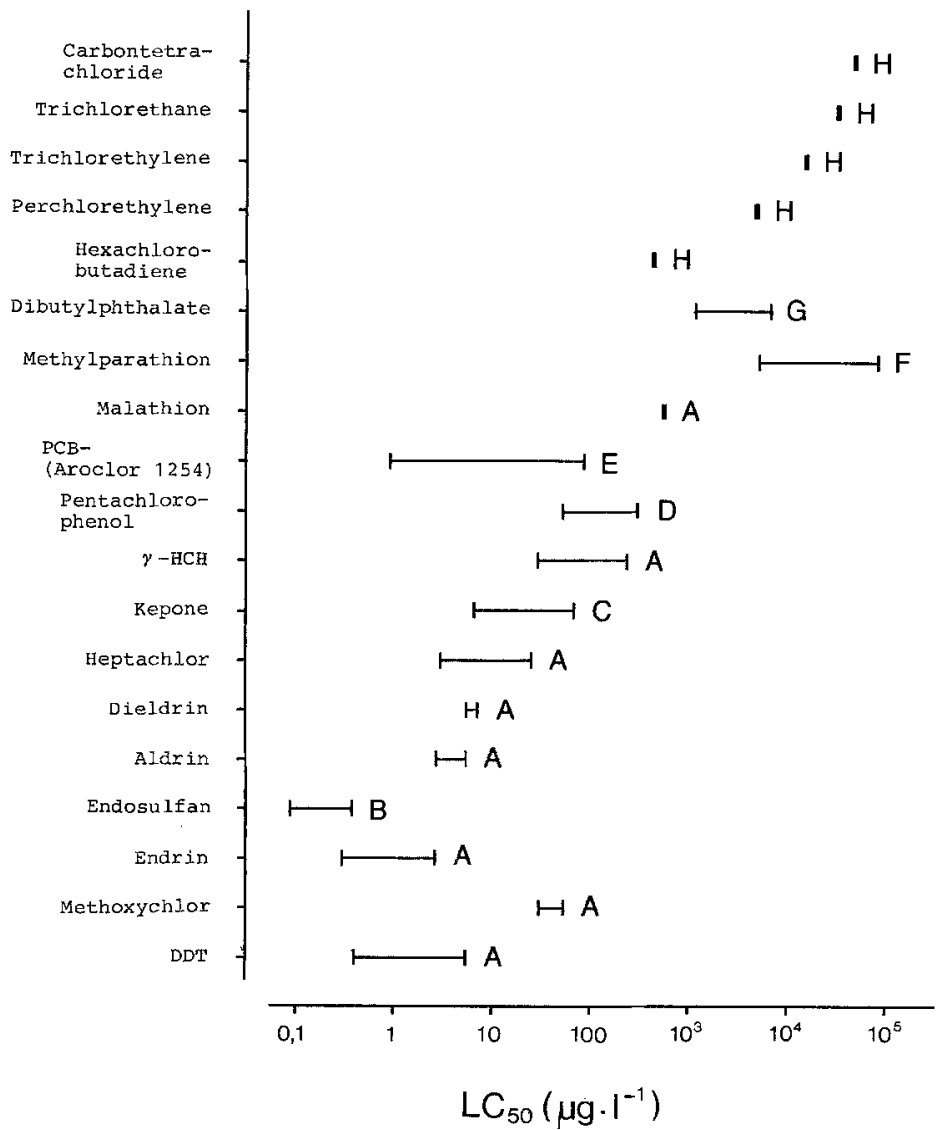

Fig. 6. Acute toxicity of pesticides and other organic substances in fish. Values for PCB: pink shrimp and crayfish. A: Holden (1973); B: Schimmel et al. (1977); C: Schimmel \& Wilson (1977); D: Schimmel et al. (1978); E: Stalling \& Mayer (1972); F: Eisler (1970); G: Peakall (1975); H: Pearson \& 


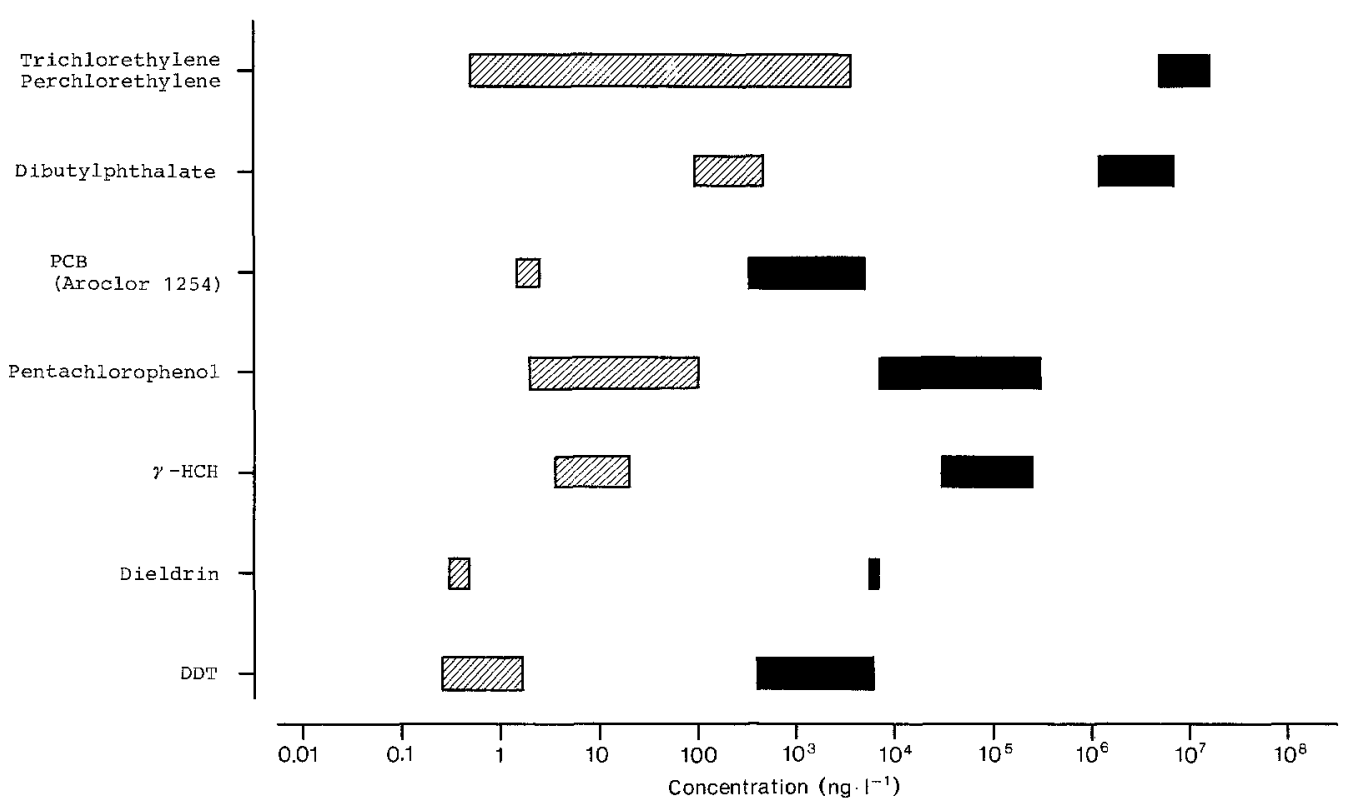

Fig. 7. Concentration of organic pollutants in water in comparison to toxic concentrations. Concentrations in water and $\mathrm{LC}_{50}$ values are from Figures 1 and 6 . Hatched bars: pollutant concentrations in sea water; black bars: toxic concentrations; toxicity data from more sensitive criteria: PCB

(Aroclor 1254) (Schimmel et al., 1974); pentachlorophenol (Tagatz et al., 1977)

chemicals to fish, e. g. species relationships, temperature, salinity, oxygen concentration, developmental stage, physiological condition, time of exposure, as well as experimental conditions such as continuous flow or static exposure. For a number of organic compounds including pesticides and technical products, the $\mathrm{LC}_{50}$ values obtained for fish by various authors are compiled in Figure 6 . With a few exceptions, values were selected for marine species over a 48 -h or $96-\mathrm{h}$ period.

The acute toxicity data have often been used in conjunction with so-called safety factors of 0.1 to 0.01 to estimate safe concentrations of chemicals for the protection of aquatic life during chronic exposure. However, these factors do not adequately consider the specific toxic actions of the individual substances. More than 10 years ago the concept of specific application factors was introduced. This defines the relationship between the acute and chronic toxicity of a chemical; the accurate estimate of the specific application factor for a chemical can be derived from maximum acceptable toxicant concentrations (MATC). The MATC can be determined in chronic exposure tests including the most sensitive life stages, $i$. e. embryos and newly hatched fry, or in tests where animals are exposed to the chemical over their entire life cycle. Numerically, the application factor AF is the quotient of the MATC and the 96-h $\mathrm{LC}_{50}$. Application factors for some pesticides show that the highest concentration without any toxic effect may be more than two orders of magnitude lower than the $96-\mathrm{h} \mathrm{LC}_{50}$ (Hansen \& Parrish, 1977; Nimmo et al., 1977).

Levels of pollutants in the environment appear to be extremely low compared with those that prove effective in toxicological laboratory experiments. A comparison is made 
in Figure 7 in order to tentatively evaluate a toxic potential represented by some organic chemicals in the sea. The actual concentrations of these pollutants in sea water cover the range from those in the open sea and estuaries. The experimental toxic concentrations are $\mathrm{LC}_{50}$ values for fish or those obtained by more sensitive criteria. It can be concluded from Figure 7 that in the open sea there are more than four orders of magnitude between environmental and any toxic levels, a safety margin wide enough to preclude any toxic effect. However, these "safety margins" are substantially smaller in estuaries and coastal areas and become additionally reduced by the following assumptions: (a) toxic actions must not be considered for a single substance but for many substances simultaneously present, each contributing an additional toxic potential; (b) biomagnification of persistent compounds in the food chain must be considered; especially substances exhibiting half-life times of more than about twenty days may be concentrated in primary and higher consumers so that toxic effects may occur at concentrations lower than those represented in Figure 7; (c) certain species may exhibit a higher degree of bioconcentration than a test species chosen; (d) estuarine sediments contain high concentrations of pollutants that contribute to higher levels in biota via benthic food chains; (e) pollutants which are at present undetectable will contribute to a higher total load especially in estuaries; (f) stress factors, such as low oxygen concentrations, will act towards a higher toxic potential.

\section{CONCLUSIONS}

From the results presented in this paper the following conclusions can be drawn: (1) The load of organic substances in sea water, sediments and biota can now be measured by highly specialized analytical techniques. Concentrations in sea water depend on depth and location; estuaries exhibit considerably higher concentrations than open sea water.

(2) Metabolic degradation does occur in marine organisms, even with highly persistent molecules although to a lesser extent.

(3) Prediction of bioconcentration potentials can be achieved by the use of partition coefficients and solubility data. Short-term experimental work in this field will be accelerated by kinetic approaches.

(4) Biomagnification of substantially persistent compounds along food chains is likely to occur with increasing elimination half lives of the substances.

(5) Relationships between the acute $96-\mathrm{h} \mathrm{LC}_{50}$ and chronic toxicity can be described by specific application factors, determined for individual substances.

(6) Concentrations of a number of organic pollutants found in the open ocean are unlikely to endanger marine life.

(7) The estuaries deserve special attention: on the basis of chronic toxicity data and realistic concentrations of the substances, a safety factor of 100-1000 seems likely to be realistic. A more detailed investigation reveals a number of facts that will drastically reduce this "safety margin". In connexion with findings that disorders in fishes are increasing, it can be concluded that estuarine pollution may exert detrimental effects on marine organisms. Because there are still considerable gaps in our knowledge, it is difficult to make reliable predictions. Basically, work in this field requires generalization and simplification so that one can view the complexity of important processes 
holistically. On the other hand, concepts or models that will account for the majority of experimental findings will be helpful in promoting future research.

\section{LITERATURE CITED}

Brodie, B. B. \& Maickel, R. P., 1962. Comparative biochemistry of drug metabolism. - Proc. 1st int. pharmac. Meet. 6, 299-324.

Butler, P. A., 1971. Influence of pesticides on marine ecosystems. - Proc. R. Soc. (B) 177, 321-329.

Chiou, C. T., Freed, V. H., Schmedding, D. W. \& Kohnert, R. L., 1977. Partition coefficient and bioaccumulation of selected organic chemicals. - Environ. Sci. Technol. 11, 475-478.

Eisler, R., 1970. Acute toxicities of organochlorine and organophosphorus insecticides to estuarine fishes. - Tech. Pap. Fish Wildl. Serv. U. S. 46, 1-12.

Eisler, R., 1972. Pesticide-induced stress profiles. In: Marine pollution and sea life. Ed. by M. Ruivo. Fishing News Books, London, 229-233.

Ernst, W., 1977. Determination of the bioconcentration potential of marine organisms. - A steady state approach. I. Bioconcentration data for seven chlorinated pesticides in mussels (Mytilus edulis) and their relation to solubility data. - Chemosphere 6, 731-740.

Ernst, W., 1979. Factors affecting the evaluation of chemicals in laboratory experiments using marine organisms. - Ecotoxicol. environ. Safety 3,90-98.

Ernst, W., Goerke, H. \& Weber, K, 1977. Fate of ${ }^{14} \mathrm{C}$-labelled di-, tri- and pentachlorobiphenyl in the marine annelid Nereis virens. II. Degradation and faecal elimination. - Chemosphere 6, $559-568$.

Ernst, W. \& Weber, K., 1978. The fate of pentachlorophenol in the Weser Estuary and the German Bight. - Veröff. Inst. Meeresforsch. Bremerhaven 17, 45-53.

Giam, C. S., Chan, H. S., Neff, G. S. \& Atlas, E. L., 1978. Phthalate ester plasticizers: A new class of marine pollutant. - Science, N. Y. 199, 419-421.

Glickman, A. H., Staham, C. N. \& Lech, J. J., 1977. Studies on the uptake, metabolism and disposition of pentachlorophenol and pentachloroanisole in rainbow trout. - Toxicol. appl. Pharmacol. 41, 649-658.

Gunter, F. A., Westlake, W. E. \& Jaglan, P. S., 1968. Reported solubilities of 738 pesticide chemicals in water, - Residue Rev. 20, 1-148.

Hansen, D. J. \& Parrish, P. R., 1977. Suitability of sheepshead minnows (Cyprinodon variegatus) for life-cycle toxicity test. In: Aquatic toxicology and hazard evaluation. Ed. by F. L. Meyer \& J. L. Hamelink. ASTM, Philadelphia, Pa., 117-126.

Haque, R. \& Schmedding, D., 1975. A method of measuring the water solubility of hydrophobic chemicals: Solubility of five polychlorinated biphenyls. - Bull. environ. Contam. Toxicol. 14, 13-18.

Holden, A. V., 1973. Effects of pesticides in fish. In: Environmental pollution by pesticides. Ed. by C. A. Edwards. Plenum Press, London, 213-253.

Jensen, S. \& Jansson, B., 1976. Methyl sulfone metabolites of PCB and DDE. - Ambio 5, 257-260.

Kobayashi, K., Akitake, H. \& Tomiyama, T., 1970. Studies on the metabolism of pentachlorophenate, a herbicide, in aquatic organisms. III. Isolation and identification of a conjugated PCP yielded by a shell fish. - Bull. Jap. Soc. scient. Fish. 36, 103-108.

Leo, A. J., 1975. Calculation of partition coefficients useful in the evaluation of the relative hazards of various chemicals in the environment. In: Structure-activity correlations in studies of toxicity and bioconcentration with aquatic organisms. Ed. by G. D. Veith \& D. E. Konasewich. Great Lakes Research Advisory Board, Windsor, Ontario, 151-176.

Lunde, G. \& Steinness, E., 1975. Presence of lipid-soluble chlorinated hydrocarbons in marine oils. Environ. Sci. Technol. 9, 155-157.

Lunde, G., Gether, J. \& Josefsson, B., 1975. The sum of chlorinated and of brominated non-polar hydrocarbons in water. - Bull. environ. Contam. Toxicol. 13, 656-661.

Mason, J. W. \& Rowe, D. R., 1976. The accumulation and loss of dieldrin and endrin in the eastern oyster. - Archs environ. Contam. Toxicol. 4, 349-360.

Metcalf, R. L., Sanborn, J. R., Lu, P.-Y. \& Nye, D., 1975. Laboratory model ecosystem studies of the degradation and fate of radiolabeled tri-, tetra-, and pentachlorobiphenyl compared with DDE. Archs environ. Contam. Toxicol. 3, 151-165. 
Murray, A., J. \& Riley, J. P., 1973. Occurrence of some chlorinated aliphatic hydrocarbons in the environment. - Nature, Lond. 242, 37-38.

Neely, W. B., Branson, D. R. \& Blau, G. E., 1974. Partition coefficient to measure bioconcentration potential of organic chemicals in fish. - Environ. Sci. Technol. 8, 1113-1115.

Nimmo, D. R., Bahner, L. H., Rigby, R. A., Sheppard, J. M. \& Wilson, A. J., Jr., 1977. Mysidopsis bahia: An estuarine species suitable for life-cycle toxicity tests to determine the effects of a pollutant. In: Aquatic toxicology and hazard evaluation. Ed. by F. L. Meyer \& J. L. Hamelink. ASTM, Philadelphia, Pa., 109-116.

Peakall, D. B., 1975. Phthalate esters: Occurrence and biological effects. - Res. Rev. 54, 1-41.

Pearson, C. R. \& McConnell, G., 1975. Chlorinated $C_{1}$ and $C_{2}$ hydrocarbons in the marine environment. - Proc. R. Soc. (B) 189, 305-332.

Poels, C. L. M., Snoek, O. I. \& Huizenga, L. J., 1978. Toxic substances in the Rhine River. - Ambio 7, 218-225.

Pohl, R. J., Bend, J. R., Guarino, A. M. \& Fouts, J. R., 1974. Hepatic microsomal mixed-function oxidase activity of several marine species from coastal maine. - Drug Metab. Disposit. 2, 545-555.

Schimmel, S. C. \& Wilson, A. J., Jr., 1977. Acute toxicity of kepone to four estuarine animals. Chesapeake Sci. 18, 224-227.

Schimmel, S. C., Hansen, D. J. \& Forrester, J., 1974. Effects of Aroclor ${ }^{R} 1254$ on laboratory-reared embryos and fry of sheepshead minnows (Cyprinodon variegatus.) - Trans. Am. Fish. Soc. 103, $582-586$.

Schimmel, S. C., Patrick, J. M., Jr. \& Wilson, A. J., Jr., 1977. Acute toxicity to and bioconcentration of endosulfan by estuarine animals. In: Aquatic toxicology and hazard evaluation. Ed. by F. L. Mayer \& J. L. Hamelink. ASTM, Philadelphia, Pa., 241-252.

Schimmel, S. C., Patrick, J. M., Jr. \& Faas, L. F., 1978. Effects of sodium pentachlorophenate on several estuarine animals: Toxicity, uptake, and depuration. In: Pentachlorophenol. Ed. by K. R. Rao. Plenum Press, New York, 147-155.

Stadler, D., 1977. Chlorinated hydrocarbons in the seawater of the German Bight and the western Baltic in 1975. - Dt. hydrogr. Z. 30, 189-215.

Stalling, D. L., Hogan, J. W. \& Johnson, J. L., 1973. Phthalate ester residues - their metabolism and analysis in fish. - Environ. Health Perspect. 3, 159-173.

Stalling, D. L. \& Mayer, F. L., 1972. Toxicities of PCBs to fish and environmental residues. - Environ. Health Perspect. 1, 159-164.

$\mathrm{Su}$, C. \& Goldberg, E. D., 1976. Environmental concentrations and fluxes of some halocarbons. In: Marine pollutant transfer. Ed. by H. L. Windom \& R. A. Duce. Lexington Books, Lexington, Mass., 370.

Sundström, G., Jansson, B. \& Jensen, S., 1975. Structure of phenolic metabolites of p,p'-DDE in rat, wild seal and guillemot. - Nature, Lond. 255, 627-628.

Tagatz, M. E., Ivey, J. M. Moore, J. C. \& Tobia, M., 1977. Effects of pentachlorophenol on the development of estuarine communities. - J. Toxicol. environ. Health 3, 501-506.

Vreeland, V., 1974. Uptake of chlorobiphenyls by oysters. - Environ. Pollut. 6, 135-140.

Weber, K. \& Ernst, W., 1978. Levels and pattern of chlorophenols in water of the Weser Estuary and the German Bight. - Chemosphere 7, 873-879.

Weil, K., Dure, G. \& Quentin, K.-E., 1974. Wasserlöslichkeit von insektiziden chlorierten Kohlenwasserstoffen und polychlorierten Biphenylen im Hinblick auf eine Gewässerbelastung mit diesen Stoffen. - Z. Wass.-Abwass.-Forsch. 7, 169-175.

Zell, M., Neu, H.-J. \& Ballschmiter, K, 1978. Single component analysis of polychlorinated biphenyl (PCB) - and chlorinated pesticide residues in marine fish samples. $-\mathrm{Z}$. analyt. Chem. 292, 97-107. 